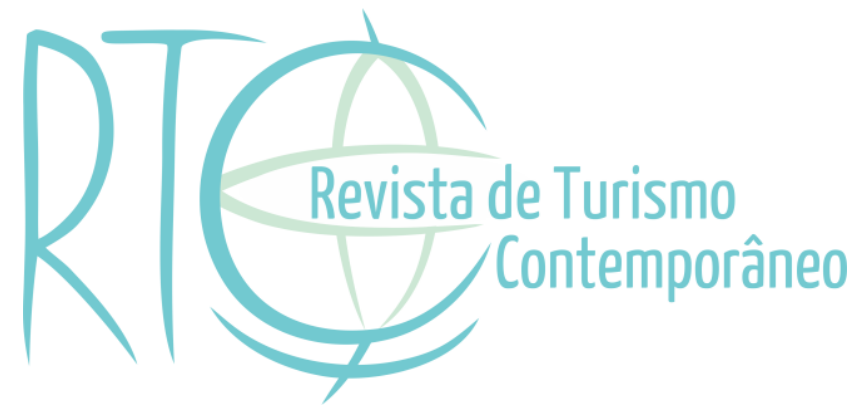

\title{
"Tour" teórico com Panosso Netto: quando tudo parece frustração e expectativa gerada é momento de olhar o passado, enfrentar o presente e construir
} Theoretical "tour" with Panosso Netto: when everything seems to be frustation and generated expectations it is time to look at the past, face the presente and build

Sylvana Kelly Marques da Silva

Doutoranda em Ciências Sociais pela Universidade Federal do Rio Grande do Norte- UFRN. Natal/Rn, Brasil.

E-mail: sylvanakelly@gmail.com

\section{Zwyla Alice Cabral Gouveia}

Mestre em Turismo pela Universidade Federal do Rio Grande do Norte-UFRN. Natal/RN, Brasil.

E-mail: zwylacabral@yahoo.com.br 


\section{RESUMO}

Este artigo tem como objetivo geral debater as críticas lançadas pelo filósofo e turismólogo brasileiro Panosso Netto aos estudos no turismo, em grande parte, de caráter funcionalista e superficial. Com efeito, o estudioso e crítico do fenômeno rejeita tanto as interpretações que traduzem o turismo a uma perspectiva objetivada, quanto as explicações que o consideram exclusivamente em sua subjetividade. Em função da sua reconhecida influência na discussão teórica do turismo no cenário brasileiro, faz-se necessário um debate com esse autor que propõe análises alicerçadas em disciplinas fundantes do conhecimento humano principalmente a filosofia e história - essenciais para a reflexão em torno dos fenômenos emergentes na sociedade contemporânea. Enfrentar-se-á suas propostas a fim de capturar as contribuições e os limites. O procedimento seguido é uma revisão teórica tanto da grande área das ciências sociais, que atua em âmbito critico, quanto das diversas obras do autor e das suas principais ideias a respeito de uma perspectiva denominada por crítica. Estabelecer-se-á uma ponte entre o filósofo Panosso Neto e os autores que atuam com a perspectiva crítica. Considera-se que o autor em questão sinaliza mudanças nos estudos em turismo e apregoa a superação de um paradigma hegemônico, oferecendo, inclusive, por sua influência no campo, a oportunidade de trazer para o centro do debate dos estudos em turismo discussões que se mantiveram na periferia da disciplina.

Palavras-chave: Turismo. Teoria. Epistemologia. Panosso Netto. Crítica.

\section{ABSTRACT}

This paper has as general objective to discuss the criticism launched by the Brazilian philosopher and tourismologist Panosso Netto to the studies in tourism, largely with a functionalist and superficial character. Indeed, the scholar and critic of the phenomenon rejects both interpretations that translate tourism to an objectified perspective, as the explanations that consider exclusively at its subjectivity. Due to its recognized influence on the theoretical discussion of tourism in the Brazilian scenario, it is necessary a debate with this author who proposes analyzes grounded in foundational disciplines of human knowledge - especially the philosophy and history - essential for the reflection on the emerging phenomena in the contemporary society. His proposals are being faced in order to capture their contributions and limits. The procedure followed is a theoretical review of both the large area of social sciences, which operates in a critical scope, as the various works of the author and his main ideas about a prospect called by critics. It Iet $^{\text {e }}$ being established a bridge between the philosopher Panosso Neto and the authors who work with the critical perspective. It is considered that the author signalizes changes in tourism studies and preaches the overcoming of a hegemonic paradigm, offering even, for his influence in the field, the opportunity to bring to the center of the debate of studies on tourism, discussions remained on the outskirts of discipline.

Keywords: Tourism. Theory. Epistemology. Panosso Netto. Critical. 


\section{CONSIDERAÇÕES INICIAIS}

O modo como os tempos sociais ${ }^{1}$ se transformam, representam, simbolizam e se constituem, são aspectos relevantes e intrínsecos à temática do turismo. É interessante considerar os tempos que cortam a história e com eles, seus mitos, as relações, as práticas, os saberes e as sociabilidades, tendo em vista a relação que esses momentos e elementos históricos possuem com o deslocamento humano no globo terrestre. $\mathrm{O}$ deslocamento, segundo Chartier (1990), caracteriza uma das várias práticas e representações humanas que foi e é capaz de construir e reafirmar identidades e representações culturais e coletivas, ou seja, de impor práticas que funcionarão em estrita analogia com as demais relações sociais.

O campo a que se refere o deslocamento humano no espaço geográfico terrestre e seus variados sentidos simbólicos está imbricado nas mais diversas formas de sociedade humana de modo plural. A sociedade moderna ${ }^{2}$, ao qual nos reportamos, impõe suas estruturas aos deslocamentos humanos, organizando-o de maneira racionalizada, política e econômica - o turismo. É nessa nova forma de sociedade que se apresenta as características de exaltação do trabalho produtivo, a industrialização, a racionalização dos momentos livres em detrimento da valorização do ócio e é o momento em que se instituíram as férias. Trata-se de um período marcado por profundas mudanças que ocasionaram o estabelecimento de uma sociedade adepta do modelo de produção capitalista, em que os bens e serviços, assim como os próprios espaços geográficos, são mercantilizados. (Massey, 2007; Harvey, 2005; Santos 1993, 1994)

Pode-se dizer, de modo geral, que se constrói um sistema social alicerçado na acumulação do capital e na produção seriada de mercadorias. Mas, para além dessa interpretação, destacam-se as estruturas sociais e as subjetividades inerentes a esse processo,

1 Como Tempo Social considera-se uma referência específica ou qualificativa de uma perspectiva mais substancial do tempo, ou seja, como um recorte da aplicação do tempo à realidade social, visto que a experiência do que se denomina tempo mudou substancialmente e continua mudando, não só de forma histórica e acidental, como de forma dirigida e estruturada. Mais informações em ELIAS, Norbert. Sobre o tempo. Rio de Janeiro: Jorge Zahar, 1984.

2 Diante das divergências teóricas em relação à modernidade ou pós-modernidade, nesse artigo corroboramos com o Cientista Social Inglês Anthony Giddens, que a nossa condição histórica é a modernidade. Período que refere-se a "organização social que emergiu na Europa a partir do século XVII e que ulteriormente se tornaram mais ou menos mundiais em sua influência". (1991: 11). O autor assume que experimentamos um período marcado pela desorientação, pela sensação de que não compreendemos plenamente os eventos sociais e que perdemos o controle. Mas, que "em vez de estarmos entrando num período de pós-modernidade, estamos alcançando um momento em que as consequências da modernidade estão mais radicalizadas e universalizadas". $\mathrm{O}$ autor percebe os contornos de uma nova ordem, mas que não rompe com a modernidade, sendo assim diferente do que é chamado por muitos de "pós-modernidade". 
"Tour" teórico com Panosso Netto: quando tudo parece frustração e expectativa gerada é o momento de olhar o passado, enfrentar o presente e construir

tais quais os conceitos, concepções, símbolos, mitos e anseios advindos dessas transformações. Ou seja, essas mudanças foram responsáveis pela geração de uma diversidade de dimensões simbólicas e imaginárias que implicam em sistemas de representações e apreciações de uma sociedade: que institui, constitui e executa suas vontades de acordo com a organização da estrutura em voga. Nesse universo de novos desejos e anseios, materializou-se a atividade turística como uma necessidade, um meio de evasão humana, ícone de status, representação de uma posição social.

Para entender e mesmo fomentar esse fenômeno plural que é o turismo, começa a surgir pesquisas que requer a análise das práticas sociais, a fim de trazer à tona um conhecimento científico que propicie o estudo continuado da atividade e das suas teias de relações nas estruturas sociais. A análise dos indivíduos, dos momentos históricos e dos espaços geográficos, assim como suas influências na sociedade, são elementos imprescindíveis. Buscando destacar a importância socioespacial e histórica interligada a dimensão individual e coletiva nos estudos das ciências sociais Trindade (2007, p. 97) afirma que é sublunar relacionar os estudos científicos ao individuo e ao seu meio, pois ambos integram-se de modo que o "ser é modificado pelo meio ao qual o próprio ser pertence e modifica".

Não é, nem poderia ser diferente com o turismo - um campo de estudo em construção, em busca de aprimoramento das bases teóricas, conceituais e metodológicas - e o reconhecimento de sua autonomia de pensamento, reflexão e postulações. Como o turismo apresenta peculiaridades que o torna múltiplo em significados e aspectos, o que segundo Echtner (1995), acontece em função da construção da disciplina ser segmentada, inter e multidisciplinar, criando alguns conflitos que dificulta o seu entendimento. $O$ fato da disciplina ser relativamente nova, também, reflete esse processo de conflitos, maturação e constituição das bases teóricas pelo qual o turismo passa e que, sem o qual, limitaria a expansão da área de conhecimento (Cooper, Shepherd, \& Westlake.,1994).

Diante do exposto, temos um cenário que apresenta um campo de análise com lacunas de conhecimento e escassez bibliográfica no que diz respeito a abordagens críticas. Esta afirmação é de certa forma, apoiada por Boterill, Gale e Haven (2002), que defendem que poucas obras foram influenciadas pela teoria crítica. Do mesmo modo, Meethan (2002) afirma que grande parte dos estudos foi realizado acriticamente e os seus efeitos mais amplos falharam ao ser avaliados.

Ateljevic (2007), em sua visão geral da área, mostra ainda que o turismo tem sido dividido entre as abordagens economicistas e sociais. A primeira muitas vezes descrita como 
objetivista e positivista, como defendem Franklin e Crang, 2001; Hollinshead, 2003, 2004; Riley \& Love, 2000; Tribe, 2005. A segunda como fragmentada e dispersa por uma série de disciplinas, como afirmam Graburn e Jafari, 1991; Phillimore e Goodson, 2004. A noção da lacuna existente na teoria substancial quanto à pesquisa em turismo foi destacada também por outros estudiosos nas últimas décadas, tais quais Dann, Nash e Pearce, 1988; Hall, 2000; Hall e Butler, 1995. Rejowski (1996) também corrobora com a afirmação que a produção acadêmica ainda é insuficiente a fim de se constituir em uma linha de pesquisa substancial, para a sustentação de uma teoria do turismo, ou seja, no desvelamento de sua epistemologia.

Fazendo uma análise a partir do ponto de vista da documentação internacional, o quadro é mais diverso e teve seu florescimento na segunda metade do século XX, mais precisamente na década de 1950, momento da reconstrução da Europa, após a Segunda Guerra Mundial. Período em que o ocidente acumulou mais conhecimento e acelerou mais o processo de transformações sociais. Esse momento histórico foi marcado pelo surgimento de inúmeras bibliografias sobre o turismo, porém, nessa volumosa massa documental com frequência, também não se debruçavam sobre os estudos por intermédio de um viés crítico (Carvalho, 1997).

Essa situação vai ao encontro de grande parte das perspectivas acadêmicas do período. E a partir de uma análise da própria história das ciências, de suas revoluções e das démarches do espírito científico sabe-se que somente a partir da segunda guerra mundial, mas precisamente da década de 1960, é que temos a chamada virada paradigmática. Movimento em que se estabelece uma mudança geral de paradigmas. Tal movimento trouxe novas interpretações para a história, sociologia, psicologia, economia e antropologia (Dosse, 2003). Essas disciplinas filiadas as grandes tradições sociológicas abraçaram inicialmente as transformações paradigmáticas segundo Santos (2002), pelo fato de estarem filiadas nas matrizes inauguradas por Marx, Durkheim e Weber e terem assim os seus estudos relacionados a enfoques clássicos ligados à atividade prática e a perspectivas críticas.

Em sequência outras disciplinas foram sendo impulsionadas a uma ampliação de seus conceitos e ideias. O que não aconteceu de forma harmônica visto que as apropriações do conhecimento, os sentidos e as transformações, mesmo ampliando-se em diferentes espaços e chegando a diversas partes do mundo nem sempre estão em sincronia. Não estão em sincronia, mas não deixam de acontecer, por exemplo, os locais considerados periféricos no qual o entendimento dos idiomas dominantes ainda se constitui em empecilho para os pesquisadores. Onde os processos de produção e divulgação do conhecimento desenvolvemse mais tardiamente, ou pela distância geográfica que ainda dificulta o acesso às produções 
"Tour" teórico com Panosso Netto: quando tudo parece frustração e expectativa gerada é o momento de olhar o passado, enfrentar o presente e construir

mais antigas, ou pela falta de incentivo das instituições de pesquisa. Principalmente quando comparados aos grandes centros, se perceberam atingidos por um turbilhão de mudanças que indicava a necessidade da reflexão do campo científico por uma visão crítica capaz de responder as questões relacionadas à problemática contemporânea.

Além, podemos acrescentar que a produção do saber turístico de modo geral, e de modo específico no Brasil, tem se constituído num conjunto de iniciativas, prioritariamente do setor privado/empresarial e menos da academia científica, sejam elas universidades e/ou faculdades, públicas ou privadas. "O saber turístico assim produzido é reduzido às informações sistemáticas sobre seu setor produtivo" (Moesch, 2002, p.13).

Mas, tem havido uma tentativa de aproximar e fortalecer os estudos que envolvem o turismo com o contexto científico, a fim de instigar a pesquisa e a construção do conhecimento na área. Visando proporcionar maior maturidade da disciplina em relação ao contexto científico em geral, e primordialmente para contribuir com a sociedade. Cientes da tábula rasa no qual se concentra grande parte dos estudos que envolvem o turismo, o artigo busca problematizar as reflexões produzidas na área tendo como fio condutor as críticas teóricas e epistemológicas propostas pelo autor Alexandre Panosso Netto.

O pesquisador aponta novos caminhos para análise dos fatores intervenientes da construção do conhecimento em turismo. Em suas reflexões Panosso Netto propõe que as discussões que permeiam a área estejam alicerçadas em estudos teóricos e epistemológicos que privilegiem a análise crítica. Indica a necessidade de se debruçar sobre a história e a filosófia. A importância que o autor dá a essas disciplinas fundantes do conhecimento humano - filosofia e história - é a de reconhecê-las como essenciais para que se possa analisar de forma crítica qualquer fenômeno emergente na sociedade moderna.

As necessidades atuais que levam os estudiosos dessa área do conhecimento a requererem o reconhecimento da "cientificidade" desses estudos, também é contextualizado e questionado pelo autor, na medida em que o caminho seguido pelas reflexões em turismo, focaram-se em aspectos parciais do fenômeno e relegaram aspectos fundamentais, indispensáveis para entendê-lo de forma mais ampla em suas consequências espaciais, temporais, sociais, psicológicas, políticas e econômicas. Contudo, vivenciamos crises de dimensões bem mais amplas, como a dos próprios paradigmas que instituíram os "saberes" da maneira que os vivenciamos.

O conhecimento científico da maneira que o concebemos atualmente passa a ser questionado, visto que é percebido como um instrumento de poder em sua dimensão político e ideológico, que serve na articulação das forças que tecem a trama social e cerceiam outras 
alternativas de existências humanas. E, nesse sentido, Panosso Netto (2011), argumenta que se esses estudos não saírem da superfície em que, em sua maioria, se encontram e derem mergulhos mais profundos, alicerçando-se em um todo espacial, temporal e social baseados na epistemologia, na filosofia e na história, não chegarão a alcançar o grau de respeitabilidade almejado entre as áreas do conhecimento.

Nesse texto o pressuposto é que não há uma única experiência fundante ou essencial nas relações que envolvem o turismo. Experiências que sejam passíveis de isolá-lo como domínio, principalmente, como conhecimento que deva ser espacialmente aplicado em detrimento de entendê-lo como a parte de um todo vinculado as experiências construídas a partir de distintas narrativas e performances sociais. Procuramos verificar como as contribuições proposta pelo teórico da área, Alexandre Panosso Netto, apreendem os estudos do turismo, de forma mais ampla,

\section{UM OLHAR AO PASSADO}

O olhar ao passado para nós significa compreender os sentidos da existência humana e da suas produções na contemporaneidade, fundamentados em sua dimensão temporal. O que significa um corte com as formas de pensamento idealistas, positivistas e fragmentados de se fazer reflexão sobre o turismo. Nesse sentido, o olhar está direcionado a perspectiva histórico-filosófica de se construir conhecimento em turismo, sugerido por Panosso Netto. Para iniciarmos o movimento do pensamento do autor, nada melhor do que contextualizá-lo em seu espaço acadêmico. É o que faremos mais adiante.

Panosso Netto é um teórico jovem e sua trajetória nos estudos que envolvem o turismo tem sido, frequentemente, marcada pela busca de ordenar, por meio de uma perspectiva humanística, a disciplina. A princípio nada parece mais óbvio do que tentar tratar por meio de uma perspectiva humana uma atividade desenvolvida por seres humanos, para seres humanos, em espaços de práticas e representações humanas. Um turismo que envolve e (des)estrutura a vida de seres humanos, que faz parte de desejos e inquietações humanas. Contudo, afirmar o que a primeira vista, pode parecer ser óbvio, exige todo um comprometimento, leituras, maturidade intelectual, entre outra série de construções e quebras de barreiras, que possibilitou o estudioso a situar sua posição.

Panosso Netto é graduado em Filosofia e em Turismo, especialista e mestre em História e doutor em Ciências da Comunicação, sendo assim, perceptível a existência de um 
"Tour" teórico com Panosso Netto: quando tudo parece frustração e expectativa gerada é o momento de olhar o passado, enfrentar o presente e construir

diferencial, para que esse tenha apreendido a necessidade de um retorno às dimensões históricas. A evolução de suas ideias está concatenada as influências de suas áreas de formação. Iniciou seus estudos na Filosofia em 1992, tendo concluído sua graduação em 1994, na Universidade Católica Dom Bosco (UCDB). Logo após, em 1995, iniciou os seus estudos em turismo, ingressando no curso de graduação que concluiu em 1998.

No mesmo ano em que concluiu a graduação em turismo deu início aos estudos na área de história do Brasil, na especialização realizada na Universidade Federal do Mato Grosso do Sul (UFMS), de 1998 a 2000. Em 1999, ampliou sua formação ao ingressar no mestrado em história do Brasil, que concluiu em 2001, na UFMS. No ano de 2000, deu início a especialização em Marketing Business Administration em Turismo: Planejamento, Gestão e Marketing pela Universidade Católica de Brasília, com conclusão em 2003, e em paralelo a especialização, no ano de 2002, iniciou o curso de doutorado em Ciências da Comunicação, pela Universidade Estadual de São Paulo (USP). Local aonde atualmente atua como professor, com dedicação exclusiva, no curso de turismo, situado no núcleo da Escola de Artes, Ciências e Humanidades - EACA.

Ao analisarmos a trajetória acadêmica do pesquisador, observamos o foco na área de humanas. Grande área que privilegia o universo teórico e epistemológico da construção dos saberes científicos. A produção bibliográfica do Professor Panosso deixa claro que os referenciais que sustentam sua linha de pesquisa são de teóricos que partem de um problematização da construção do próprio conhecimento científico, como pode ser observado em suas produções desde 2005 até os dias atuais.

$\mathrm{O}$ pesquisador de posse de distintos conceitos, teorias e fundamentos se debruçou sistematicamente na pesquisa sobre a produção do conhecimento na área do turismo. Pesquisou os estudos desenvolvidos em turismo dos anos de 1990 a 2007. Realizou levantamentos de materiais que auxiliam na reflexão desse processo de construção do conhecimento em suas distintas temporalidades. De maneira criativa o autor Panosso Netto (2005) sugere que: assim como a historiografia está para a história; através de uma análise cuidadosa sobre o turismo, a "teorografia" estaria para o estudo do turismo. Orientando à origem da produção científica em turismo.

Em relação aos estudos que se constroem em turismo, ao envolvimento entre as partes interessadas nesses estudos, Panosso Netto nos afirma que: “é comum perceber nas escolas de turismo professores que se recusam a exigir maiores reflexões críticas de seus alunos simplesmente pelo fato de que os alunos não desejam se debruçar sobre temas considerados áridos e difíceis." Esse é um comentário que nos permite pensar a fragmentação, 
a ausência de uma racionalidade crítica, que encontramos em diversas áreas da vida cotidiana, principalmente em relação à recepção das informações que nos invade de maneira superficial e recortada, sem estabelecermos sobre elas uma criticidade. Essa superficialidade atinge o espaço, por excelência, designado para o da formação de um pensamento crítico. Nas palavras do pesquisador "mesmo no lugar ideal para a reflexão, ela é negada." Sendo urgente a atenção para a fragilidade que envolve as teorias, as pesquisas, os estudos e o próprio envolvimento dos profissionais que se debruçam sobre os estudos em turismo (Panosso Netto, 2010).

As inquietações expostas pelo estudioso são desconfortantes na medida em que mostram que nesse segmento "tudo parece estar em crise". Ou seja, os estudos de turismo tem dificuldade de incluir em suas reflexões aspectos críticos e complexos da própria vivência humana no qual o fenômeno, por mais que pareça ausente, encontra-se imbricado, como por exemplo, na vida cotidiana. As teorias que buscam explicar a ordem social desse fenômeno quando se propõem a isso, pois grande parte das reflexões contenta-se em aplicá-lo e avaliar as possibilidades de retorno financeiro para certos grupos -, suas estruturas, conjunturas e seus códigos culturais teriam ainda grandes barreiras ao analisar muito daquilo que pertence ao turismo. E principalmente tudo aquilo que aparentemente escapa dele. O certo é que apreender o fenômeno do turismo envolve uma grande complexidade, o que deve expulsar, no sentido exposto pelo filósofo Morin (2005, p. 15), os paradigmas simplificadores, e ainda não há um consenso sobre isso entre os estudiosos da área.

Muitos teóricos que se debruçam sobre o estudo do turismo, são graduados em outras disciplinas, com uma maior concentração nas áreas aplicadas, fato percebido pelo autor como um empecilho existente para esses estudos, pois acaba direcionando as pesquisas para outros objetivos. Não encadeados em uma análise mais profunda do fenômeno, tendendo assim, a limitar esses estudos, que acabam por reproduzir e replicar conhecimentos sem a perspectiva de uma análise mais comprometida com a própria disciplina, de um devir em relação às estruturas e aos códigos socioespaciais que envolvem a atividade.

As categorias de estudos em turismo têm sido construídas pensadas a partir de paradigmas e concepções ligados à ciência dos pesquisadores que se debruçaram sobre o tema, compartimentadas nos objetivos diretos de cada um desses distintos campos do saber. Essa especialização de conhecimentos deixa escapar um comprometimento entre a interação e a análise, que deveria estar a todo tempo se intercomunicando com os saberes relacionados ao turismo e a análises que envolvem aspectos mais profundos e plurais da sociedade humana. Esse tipo de divisão dificulta mais ainda uma direção ou mesmo um senso comum entre os estudos desenvolvidos no turismo (Panosso Netto, 2009). 
"Tour" teórico com Panosso Netto: quando tudo parece frustração e expectativa gerada é o momento de olhar o passado, enfrentar o presente e construir

O problema específico não é de se pensar o turismo, a partir de outras disciplinas, mas principalmente de compartimentá-lo no interior dessas disciplinas, separando dimensões essenciais que o envolve. Para exemplificar, podemos pegar o exemplo da disciplina de economia, que sabemos que possui renomados autores críticos que direcionam suas análises de maneira contextualizada aos códigos humanos e culturais, porém existe nesse campo, ainda uma grande tendência a concentração das pesquisas na área legitimadas pela comercialização do conceito, em favor de uma ideia que converge sobre os impactos, principalmente os econômicos. Geralmente, os pesquisadores da área ao se interessarem pela atividade turística, não se debruçam em torno de uma busca histórica e filosófica de conceitos capazes de dar um maior entendimento ao fenômeno e as suas relações com os diferentes níveis da sociedade e do ser humano. Ao contrário, tendem a utilizar conceitos superficiais da atividade, guiados por fatores econômicos, que acaba sendo a dimensão que prevalece sobre vários aspectos da sociedade, fazendo com que haja uma valorização da comercialização de valores, comportamentos e dos próprios seres humanos (Panosso Netto, 2009).

Nas análises propostas por Panosso Netto há uma evidente preocupação em estabelecer uma base teórica para o turismo, que possa se consolidar de maneira sólida, com definições mais precisas. Mas, dizer sólida, não significa partir do ideal científico aristotélico, no qual a ciência estaria em condições de propiciar um saber definitivo, longe disso. "Como toda verdade humana, também a verdade científica é „filha do tempo “; toda verdade que se pretenda fora do tempo, degenera, transformando-se em dogma ou em mito" (Japiassu, 1999, p. 03). Sobre esse aspecto podemos beber nas fontes de Karl Popper, que parecia coberto de razão ao afirmar que não devemos nos deter na busca de um caminho rígido, passível de nos conduzir a verdades definitivas, mas sim de enquanto pesquisadores, ousarmos ir à busca de hipóteses, de direções que nos acrescente um alto grau de valor informativo, além dos horizontes observáveis. Se os cientistas não tivessem ousado, certamente muito do que conhecemos não seria possível Popper (1963 como citado em Carvalho, 1991,pp. 65-93).

Se tomarmos a proposta de Popper como exemplo, se como pesquisadores nos motivarmos para a construção de conhecimentos críticos na área do turismo, se buscarmos ousar, examinar o fenômeno em suas nuances, teremos antes, segundo Panosso Netto, que medi-lo, legislá-lo, promovê-lo, que significa definir o que isso abrange. Para buscar esclarecer o ponto de vista do autor, entender a centralidade de sua análise, a afirmação feita por Tribe (1997, p. 638), que define como complexa e multifacetada a natureza da atividade turística, pode ser esclarecedora: 
Os estudos relacionados ao turismo tem se pautado por uma ampla variedade de abordagens realizadas através das mais diversas disciplinas, como a economia, a psicologia, a antropologia, a geografia, o planejamento urbano, a administração, dentre outras. Isto se deve ao alto grau de complexidade do fenômeno turístico e de suas múltiplas facetas. Dentro desse universo, verifica-se que grande parte do conhecimento produzido se caracteriza por uma aproximação mais pragmática, que busca desenvolver processos e formas de agir e intervir na realidade. Podendo ser chamado de saber proporcional e, muitas vezes patrocinado por agentes e instituições interessados no seu desenvolvimento, enquanto aqueles estudos que tem por objetivo aprofundar a compreensão do fenômeno turístico em si, relacionados ao saber processual, apresentam avanços bem mais tímidos.

Há deste modo um direcionamento para a importância não só de conhecer, mas também de definir o fenômeno do turismo e o estudo do turismo (Panosso Netto, 2009). Podemos fazer uma analogia da preocupação do teórico Panosso Netto, com o pensamento complexo de Morin (2005), no sentido em que Panosso Netto, ressalta a necessidade da caracterização da área, da busca por suas próprias finalidades, mas sem perder a harmonia com os demais sistemas com os quais interage. Ainda, em interação entre o pensamento dos filósofos em questão, vale ressaltar que Panosso Netto se opõe ao simplismo paradigmático, no momento em que exalta a necessidade de criar para o campo do turismo suas definições, suas determinações, seus sistemas de auto-organização. Sem, contudo, deixar escapar as dimensões que o envolve, todos os sistemas com os quais o fenômeno está integrado nas diferentes temporalidades e espacialidades.

Diante do atual contexto em que estão inseridos os estudos do turismo é recorrente nas diversas produções do autor, a busca de soluções conceituais, teóricas, metodológicas. A investigação por respostas de âmbito epistemológico e ontológico, não só para superar a crise que se vivencia no conhecimento em turismo, fator primordial para reconhecimento e futuro vigor da disciplina, mas para também nos dar condições de, enquanto pesquisadores, legitimar nossa área de atuação, como uma disciplina acadêmica relevante. Significativa por estar imersa nas relações produzidas entre os seres humanos, por ser também um produtor dessas relações humanas e por ser, antes de tudo, impraticável a construção de um conhecimento sem ter em conta sua inscrição no espaço, a história dos seus usos, suas características e funções, a proliferação de seus modelos e suas relações objetivas e subjetivas com os sujeitos da história.

Apreender essas particularidades é condição essencial para se pensar em um campo de estudo, capaz de dar subsídios à construção de novos questionamentos e reflexões para os pesquisadores da área. Através das inquietações apontadas por Panosso Netto, podemos levantar as seguintes interrogações: Qual o lugar que o turismo ocupa nas instituições públicas e privadas? Em consonância com o histórico dessa atividade, como os 
"Tour" teórico com Panosso Netto: quando tudo parece frustração e expectativa gerada é o momento de olhar o passado, enfrentar o presente e construir

estudos que se debruçam sobre ela se comportam? Como esses estudos entendem o turismo? Qual é o objeto do estudo do turismo? Quais as nossas metodologias? Como estão organizadas as nossas fundamentações teóricas? Quais as tecnologias que utilizamos para pensar a relação do turismo com o homem, com o espaço, com a sociedade?

Não é nosso interesse responder questões como essas em um curto texto, mesmo que fosse seria impossível, visto a complexidade que as envolve, mas são questões pertinentes de serem colocadas, pois nos levam a problematizar a área de conhecimento no qual estamos imersos. E, nos ajuda a esclarecer a seriedade e a profundidade do caminho que este conhecimento reclama. Se aceitarmos, como enunciou um dos mais conceituados intelectuais brasileiros, com seus estudos que superaram as fronteiras nacionais, Milton Santos (1996) aponta que: toda disciplina deve ter uma reflexão, suas próprias tecnologias, metodologias, um corpo de discussão teórico e seu objeto, senão de senso comum, será uma pobreza, podemos intuir o quão pertinente e urgente são as "buscas" de Panosso Netto. Este alega que por meio da teorização, será possível a construção de reflexões que levem a compreensão crítica da realidade (Panosso Netto, 2010).

Nessa perspectiva de reflexão crítica o autor direciona o sentido aos estudos do turismo, que deve ser privilegiado, principalmente, no espaço destinado para a formação e avaliação dos pensamentos e construções humanas, as universidades. Estudos que devem estar pautados em um mergulho teórico, nos pensamentos, nas obras clássicas. No sentido dado por Bobbio (2007), para garantir um lugar entre os clássicos, o pensamento descrito deve interpretar de tal maneira a época em que viveu, que não se possa prescindir dele para conhecer o sentido do tempo, para interpretar uma realidade, mesmo que seja distinta daquela a partir do qual derivou-se suas categorias de análise. Por sua vez, a proposta de Panosso Netto é nuclear aos estudos do turismo, por buscar restituir o olhar ao passado, sem o qual é impossível entender o presente e construir um futuro.

\section{ENFRETAMENTO COM O PRESENTE}

O olhar ao passado, sugerido pelo pesquisador Panosso Netto, no decorrer de sua produção acadêmica, implica em um enfrentamento com a maneira pela qual se constroem os saberes no campo do turismo no tempo presente. São perspectivas de estudos, que buscam o enfrentamento das crises atuais por meio do questionamento de categorias de análises até então cristalizadas. Problematizações em relação ao tipo de desenvolvimento no campo 
acadêmico que circundou a atividade turística. Uma busca em relação à dimensão história e espacial do fenômeno e, principalmente aos aspectos críticos que o envolvem. As ideias críticas que permeiam os estudos do Professor Panosso Netto, situam-se no seguimento dessa corrente de estudos, que à grosso modo, podemos afirmar que inicia-se na década de 1980 .

Para entendermos os desdobramentos que proporcionaram o surgimento desses debates nos estudos em turismo, podemos lançar um olhar panorâmico, mesmo que em certos aspectos de forma reducionista a história das ideias que se desenvolveram no decorrer do século XX. Em aspectos gerais, esse direcionamento abre questões centrais, fundamentais para que exista o raciocínio crítico e vai ao encontro da proposta do pesquisador Panosso Netto para que seja realmente construído em turismo um conhecimento, que surja de um olhar aguçado.

O "fenômeno" do turismo cada vez mais emerge como um fator determinante e condicionante, mas não em si mesmo, especialmente pelo aspecto econômico que o engendra, como um gerador de espaços, produtor de novos cenários sociais, políticos e culturais, que se incrustam. Com sua capacidade circuladora e padronizadora, promove modificações nas práticas e representações cotidianas (Meneses, 2002). Modificações que precisam ser entendidas, analisadas, teorizadas e não somente descritas, replicadas. Nesse sentido, o autor percebe a importância das discussões sobre o turismo partindo de um embasamento teórico capaz de contribuir de modo efetivo para a produção de novos cenários, sugerindo novos olhares.

Segundo Hobsbawm (2009), a ciência reflete a sua época e a maioria dos seres humanos atua como historiadores: só em retrospecto reconhece a natureza de sua experiência. Como seres sociais, somos influenciados por nossa posição sócio-espacial e temporal, por nossos signos, nossa linguagem e nossos sentidos. Não somos capazes de entender o mundo em que vivemos hoje, chamado de sociedade moderna (Giddens, 2001), sem levarmos em conta esta dimensão das relações e práticas sociais. A própria passagem da modernidade e suas transformações, só pode ser percebida, como defende Harvey (2005), a partir da compreensão de que vivemos uma nova forma de relação com o tempo e com o espaço.

Para entendermos esse contexto vale ressaltar como assinala Hobsbawm (2009) que nenhum período da história foi mais penetrado pelas ciências, nem mais dependente delas do que o século XX. Portanto, nenhum período desde a retratação de Galileu se sentiu menos a vontade com elas. Este é o paradoxo que tem de enfrentar o cientista do século. Em uma breve retrospectiva observamos que em 1910 a comunidade científica chegava a 8 mil pessoas. Em fins da década de 1980 era cerca de cinco milhões, quase um milhão pertencia 
"Tour" teórico com Panosso Netto: quando tudo parece frustração e expectativa gerada é o momento de olhar o passado, enfrentar o presente e construir

aos EUA, maior potência científica. Mesmo ainda sendo uma minúscula fração da população, os cientistas cresceram de maneira impressionante. Em fins da década de 1980 eles poderiam ser o que se chamaria de uma mão de obra científica e tecnológica potencial, refletindo a revolução educacional da segunda metade do século XX (Hobsbawn, 2009).

Apesar de $90 \%$ dos trabalhos científicos serem publicados em inglês, russo, francês e alemão a ciência eurocêntrica finalizou no séc. XX. A era das catástrofes e o triunfo temporário do fascismo transferiu seu centro para os EUA e outros países de colonização europeia se estabeleceram como grandes centros científicos. Inseridos no atual contexto, com mudanças éticas e metodológicas, os estudos e pesquisas adequaram-se as novas práticas, teorias e tecnologias, mudaram no decorrer do século XX sua maneira de olhar, desenvolvendo cada vez a importância das ciências humanas e sociais, recobrindo hoje um campo transdisciplinar combinando tendências que se aglutinam e que as fundamentam (Hobsbawn, 2009). Nesse sentido, uma das características científicas do século XX é a humanização das Ciências Humanas, sendo esse um século de grandes extremos, transformações, contribuições e de mudanças de paradigmas que nos últimos vinte anos mapearam significativamente os campos das ciências.

Tantas mudanças ocorreram por que o mundo mudou, um dos grandes historiadores da atualidade que discute as questões teóricas das ciências humanas, o francês Dosse (2003) exalta que o essencial, para se compreender o porquê da crise nas ciências sócias é percebermos que vivemos nessas ciências uma virada nos questionamentos e, agora se interroga sobre o papel do ator, sobre o indivíduo, articulado à sociedade. As ciências humanas estão em direção à prevalência de uma abordagem hermenêutica, no qual o sentido passa a ser a pergunta central, a interpretação dos sentidos passa a ser a preocupação básica. As ciências humanas trás que a relação do homem com o mundo é mediada pelos símbolos. Nós humanos dotamos todas as coisas de significados e sentidos, por isso operamos sempre na relação natureza e cultura.

Tudo o que nós humanos fazemos é ao mesmo tempo natureza e cultura, natureza e subjetividade, não há como separar a natureza, subjetividade e sociedade, como foi feito no iluminismo. Uma característica do nosso tempo é justamente essa reaproximação, a separação que foi fundante no século XIX está sendo revista hoje. No século XIX, onde a busca pela verdade total, pela razão prevalecia, as ciências humanas, para se constituírem tiveram que criar um espaço epistemológico, paradigmático, distinto das ciências naturais, da filosofia e das artes. Estamos agora vivendo o momento oposto, onde as ciências humanas se reaproximam dessas áreas. As relações humanas se dão através do sentido, dos símbolos e da 
linguagem, pois não nos relacionamos com o mundo em sua natureza, com o real sem qualquer elaboração simbólica que o organize, por isso as buscas conceituais. A verdade continua sendo uma meta para as ciências humanas em geral, mesmo que hoje saibamos que não chegaremos a ela de uma forma absoluta. Porém continuamos em busca de fazer sentido (Dosse, 2003).

Para Dosse (2003), esse momento que estamos vivendo é o momento de fazermos sentido, da busca progressiva, de construir os sentidos para as coisas. Na atualidade não há a busca de um conceito revelador da verdade, mas sim de uma verdade que vamos construindo, negociando, dialogando e mediando os sentidos como uma construção social e coletiva. Verdades estabelecidas, dialogadas e instituídas que nascem através dos segmentos e regras, que nascem das negociações e também dos conflitos. Vivemos a recuperação da dimensão política das ciências humanas, que no positivismo havia sido negada. O positivismo definia o cientista e a ciência como alguém neutro, fora do mundo simbólico. Hoje vivemos a percepção da construção da ciência e o retorno do político. As ciências humanas recolocam o homem no centro das próprias ciências, deixa de procurar a matematização e a quantificação como sendo as estruturas fundamentais.

Nesse norte se direciona o pesquisador Panosso Netto, atento as questões atuais nos campos epistemológicos já consagrados academicamente. Assim, objetiva a aproximação do turismo com a filosofia. Não há como negar que o que se mostra sobrevém da filosofia e, é de certa maneira de juízo complexo, sendo assim exige uma atenção meticulosa. As pesquisas em turismo, como almeja Panosso Netto devem ser exemplos da comunicação humana, dotados de sentidos, socialmente definidos. Todos os pesquisadores que partirem desses princípios serão filósofos, no sentido universal de que todos os seres humanos (...) são guiados por princípios abstratos, que combinam crenças sobre ontologia, epistemologia e metodologia. Formando um esquema básico interpretativo, denominado paradigma (Denzin \& Lincoln, 2006, p.34). Paradigmas esse, no sentido elaborado pelo físico Thomas Kuhn, que entendemos por regras de produção de conhecimento (Kuhn, 1962).

\section{REINVENTADO NOVOS CAMINHOS}

Vale, por fim, retomarmos algumas ideias de Thomas Kuhn para iluminar o modo como acreditamos que o autor tenha norteado suas reflexões. Para Kuhn (1995) a história de uma ciência não deve ser considerada como um processo evolutivo, mas transformada por 
"Tour" teórico com Panosso Netto: quando tudo parece frustração e expectativa gerada é o momento de olhar o passado, enfrentar o presente e construir

revoluções paradigmáticas. Revoluções que provenham ou incitem crises no seu meio da pesquisa, a ponto de alterar ideias básicas de uma sociedade sobre o mundo. Após uma revolução, há um árduo período de depuração de novas teorias e experimentos.

A ciência normal é basicamente cumulativa e seu trabalho sobre certos paradigmas tende a constituição de regras que devem reger todos os eventos. Até que essas não sejam mais adequadas. Há então uma crise da ciência normal, que Kuhn vê resolver-se de três modos: mostra-se eficaz para absorver os novos problemas e resolvê-los a partir dos seus paradigmas; ou não os resolve e, caso não surja nenhum outro procedimento intelectual capaz de esclarecê-los, esses problemas são deixados de lado; ou então vemos surgir dessa crise novos procedimentos que não se enquadram na ciência normal existente e nortearão novos paradigmas (Kuhn, 1995).

Kuhn (1995) adverte que, tais crises e mudanças de paradigmas não devem ser entendidos sempre como algo interno as ciências, mas muitas vezes como influência de fatores externos, sejam esses ideológicos, religiosos ou tecnológicos. Tais argumentos de Kuhn interessam aqui porque esse trabalho analisa um autor que busca entender e organizar as produções acadêmicas existentes na área do turismo, ao mesmo tempo em que tenta direcionálas por intermédio de instrumentos teóricos e metodológicos em voga, como foi discutido. Já que Panosso Netto disserta sobre uma crise no paradigma fundamental que orientam os estudos do turismo. O princípio básico então é alimentar novos paradigmas, que levados ao seu máximo, em outros contextos serão colocados novamente em xeque.

Entendido o momento de crise ressaltado pelo autor, podemos passar a uma questão que atravessa as principais obras de Panosso Netto. Qual é ou qual foi o paradigma do turismo? Em um de seus recentes artigos publicado em 2011, o autor relata sobre a existência tácita do positivismo como um paradigma no turismo. Panosso Netto (2011) situa grande parte das produções inseridas nos métodos positivistas, identificando que as pesquisas se atêm em sua maioria em investigar os turistas; as relações entre os turistas e os residentes; as estruturas e o funcionamento do sistema e os impactos do turismo. Uma visão científica imediatista, descritiva, metódica, economicistas e de grande tendência à quantificação e a estudos de caso, negligenciando de certa forma as reflexões mais profundas, que possam trazer maiores contribuições e clareza para o debate.

Quando Panosso Netto (2005) busca um retorno à origem da produção científica em turismo, ele também oferece um caminho teórico e metodológico como sugestão: a fenomenologia. Que tem suas raízes em fins do século XIX, mas se constituiu no século XX, tendo como timoneiro Edmund Husserl. A partir de uma análise rigorosa do fenômeno da 
consciência, a fenomenologia pretende fazer da filosofia uma ciência que descreva nossa experiência do mundo. É através do pensamento fenomenológico que o autor em questão indica as direções para novos estudos em turismo.

A fenomenologia representa uma tendência dentro do idealismo filosófico e dentro deste, do idealismo subjetivo. Sua ideia fundamental é a noção de intencionalidade e isto faz com que reconheça que não existe objeto sem sujeito, opondo-se particularmente nesse aspecto ao positivismo, que acredita não existir essa relação, pois prega a neutralidade do pesquisador ante do objeto. Sendo este entre outros, um dos grandes méritos dessa corrente filosófica, pois questionou os conhecimentos positivistas, elevando a importância do sujeito no processo da construção do conhecimento. Desse mesmo modo, o autor questiona os estudos positivistas e trás o humano para o centro da questão nos estudos em turismo.

\section{CONSIDERAÇÕES FINAIS}

Panosso Netto ao sugerir a fenomenologia como guia para os estudos em turismo, apresenta um suporte teórico, um método de pesquisa e de análise, um caminho entre muitos que podem ser percorridos. Contudo, esse caminho indicado entre outros tanto possíveis, direciona a um encontro com a história das ideias, da filosofia, das ciências e das próprias estruturas e subjetividades que engendram nossa sociedade. Pois o desconhecimento da história das ideias leva a desconfortável situação, de se abraçar ao primeiro conceito que aparece para atribuirmos uma lógica ao nosso trabalho, na maioria das vezes sem uma análise crítica desse conteúdo. Para nós parece que aí reside o objetivo principal do Professor Panosso Netto, que não está em direcionar uma estrada de análise, entre outras ordens de conceitos que servem também para reflexão, explicação e interpretação do fenômeno. Mas, sim questionar os atuais caminhos da produção do conhecimento em turismo e suas relações. Incitando ao embasamento filosófico sólido e ao conhecimento da história. Pois só esse retorno as matrizes de nossas bases racionais, é capaz de propiciar o rompimento com certas naturalizações, é capaz de propiciar a dúvida diante de conceitos estabelecidos, que conformam verdades e nos direcionando ao que passa a ser majoritariamente interpretado como correto. O que iria ao encontro da proposta de uma visão crítica que percorre a escrita do autor. 
"Tour" teórico com Panosso Netto: quando tudo parece frustração e expectativa gerada é o momento de olhar o passado, enfrentar o presente e construir

\section{REFERÊNCIAS}

Albuquerque Junior, D. M. (2008). Nos destinos de fronteira: história, espaços e identidade regional. Recife: Bagaço.

Ateljevic, I. (2007). What is "critical" about critical tourism studies? Paper presented at Wageningen University, The Netherlands.

Bobbio, N. (2007). Estado, Governo, Sociedade, para uma Teoria Geral da Política. (14a Ed.). São Paulo: Paz e Terra.

Botterill, D., Gale, T., \& Haven, C. (2002). A survey of doctoral theses accepted by universities in the UK and Ireland for studies related to tourism 1990-1999. Tourist Studies, 2(3), 283-3.

Carvalho, M. C. M. (1991). Construindo o saber: metodologia científica, fundamentos e técnicas.(3a ed.). Campinas: Papirus.

Carvalho, M. G. (1997). Tecnologia, desenvolvimento social e educação tecnológica. Revista Educação \& Tecnologia. Curitiba: Centro Federal de Educação Tecnológica do Paraná.

Castillo Nechar, M., Panosso Netto, A. (2010).Epistemología del turismo: Estudios críticos. México:Trillas.

Chartier, R. (1990). A história cultural: entre práticas e representações. Rio de Janeiro: Bertand.

Chiozzotti, A. (2003). A pesquisa qualitativa em ciências humanas e sociais: evoluções e desafios. Revista Portuguesa de Educação, 16(2), 221-236.

Cooper, C.; Shepherd, R.; Westlake, J. (1994). Tourism and hospitality education.

Guildford: University of Surrey.

Dann, G., Nash, D., \& Pearce, P. (1988). Methodology in tourism research. Annals of Tourism Research, 15, 1-28.

Denzin, N, K. Lincoln, Yvonna S. (2006). O planejamento da pesquisa qualitativa: Teorias e abordagens. Porto Alegre: Artmed.

Dosse, F. (2003). O império do sentido: a humanização das ciências humanas. Bauru, SP: EDUSC.

Echtner, Charlotte M. (1995). Tourism education in developing nations a three pronged approach. Tourism Recreation Research, 20.(2), 32-41.

Evangelista, J. E. (2007). Teoria social pós-moderna: introdução crítica. Porto Alegre: Sulina.

Fabri, M. (2007). Fenomenologia e cultura: Husserl, Levinas e a motivação ética do pensar. Porto Alegre: Edipucrs. 
Franklin, A., Crang, M. (2001). The trouble with tourism and travel theory. Tourist Studies, $1(1), 5-22$.

Giddens, A. (2001). As consequências da modernidade. São Paulo: Unesp.

Graburn, N. H. H., \& Jafari, J. (1991). Intoduction; Tourism Social Science. Annals of Tourism Research, 18, 1-11.

Hall, M. (1991). Tourism as a subject of post-graduate dissertation in Australia. Annals of tourism research, 18 ( 3),520-523.

Hall, M., Butler, R. W. (1995). Search of Common Ground: Reflections on sustainability: Complexity and Process in the Tourism System: A Discussion. Journal of Sustainable Tourism, 3(2), 99-105.

Harvey, D. (2005). A Produção Capitalista do Espaço. São Paulo: Annablume.

Hobsbawm, E. (2009). Era dos extremos:o breve século XX:1914-1991. São Paulo: Companhia das Letras

Hollinshead, K. (2003). Symbolism in tourism: Lessons From "Bali 2002". Lessons From Australia's Dead Heart. Tourism Analysis, 8(2), 267-295.

Hollinshead, K. (2004). A premier in ontological craft: the creative capture of people and places through qualitative research. In: Phillimore, J. \& Goodson, L. (Eds.), Qualitative research in tourism: Ontologies, epistemologies and methodologies.,. London: Routledge.

Japiassu, H. (1999). Paixões da ciência. (2a ed.). São Paulo: Letras \& Letras.

Kuhn, T. (1995). A estrutura das revoluções científicas.(5a ed.). São Paulo: Perspectiva.

Massey, D. (2007). Pelo Espaço: uma nova política da espacialidade. Rio de Janeiro: Bertrand Brasil.

Meethan, K. (2002). Tourism in global society: Place, Culture, Consumption. Basingstoke, England: Palgrave.

Meneses, U. A.(2002). Paisagem como fato cultural, In: Yázigi, Eduardo (Org). Turismo e paisagem. São Paulo: Contexto

Mioranza, C. (2008). Filosofia: origens, conceitos, escolas e pensadores. São Paulo: Escala Educacional.

Moesch, M. (2002). A produção do saber turístico. São Paulo: Contexto.

Morin, E. (2005). Introdução ao Pensamento Complexo. Porto Alegre: Sulina.

Panosso Netto, A., Noguero, F. T., Jäger, M. (2011). Por uma visão crítica nos estudos turísticos. Revista Turismo em Análise. 22 (03). 
"Tour" teórico com Panosso Netto: quando tudo parece frustração e expectativa gerada é o momento de olhar o passado, enfrentar o presente e construir

Panosso Netto, A. (2009). What is Tourism? Definitions, Theoretical Phases and Principles. In: John Tribe. (Org.). Philosophical Issues in Tourism. Londres: Channel View Publications, Panosso Netto, A. (2005). Filosofia do turismo: teoria e epistemologia. São Paulo: Aleph.

Phillimore, J., Goodson, L. (2004). Qualitative research in tourism. London: Routledge.

Pinto, Á. V. (1979). Ciência e existência: problemas filosóficos da pesquisa científica. Rio de Janeiro: Paz e Terra.

Rejowski, M. (1996). Turismo e pesquisa cientifica: pensamento internacional x situação brasileira. (7a ed.). Campinas, SP: Papirus.

Riley, R. W., Love, L. L. (2000). The state of qualitative tourism research. Annals of Tourism Research, 27(1), 164-187.

Santos, F. (2002). Turismo mosaico de sonhos. Lisboa: Colibri.

Santos, M. (1994). Técnica, espaço e tempo: Globalização e meio técnico-cientificoinformacional. (2a.ed.). São Paulo, HUCITEC.

Santos, M. (1993). A urbanização brasileira. São Paulo: HUCITEC.

Tribe, J. (1997). The indiscipline of tourism. Annals of tourism research, 24,( 3), 638-657.

Tribe, J. (2005). New Tourism Research. Tourism Recreation Research: Theme - Tourism and Research, 30(2), 5-8.

Trindade, A. (2007). Os direitos fundamentais em uma perspectiva autopoiética. Porto Alegre: Livraria dos Advogados. 